
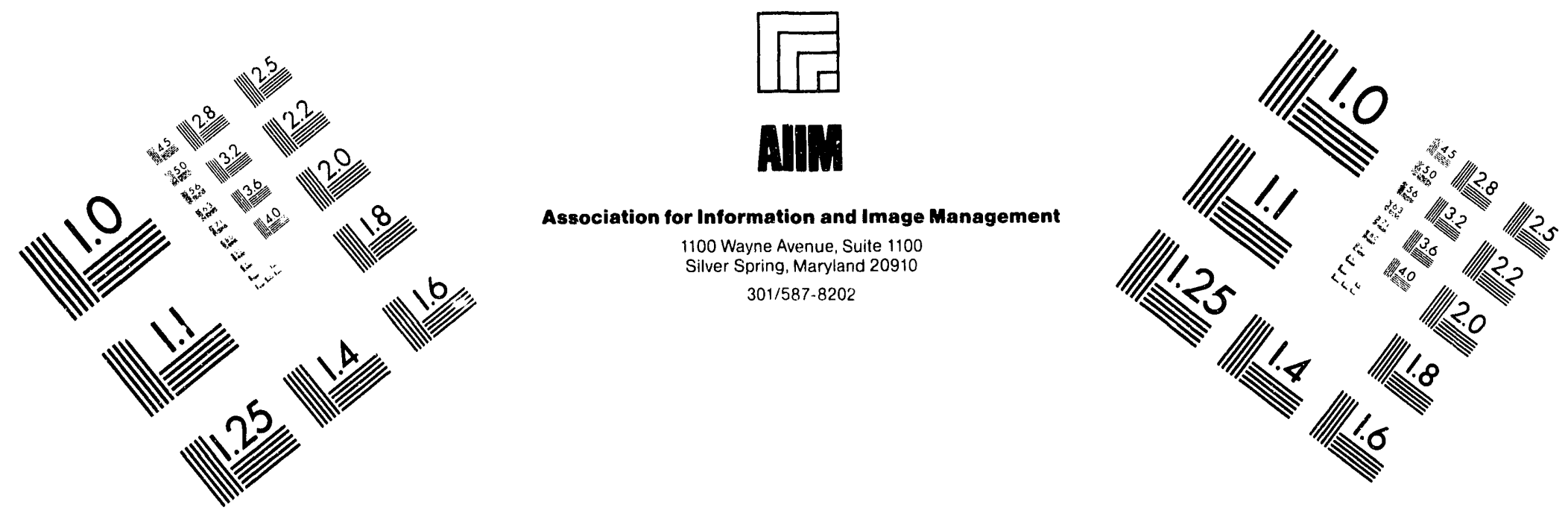

Centimeter

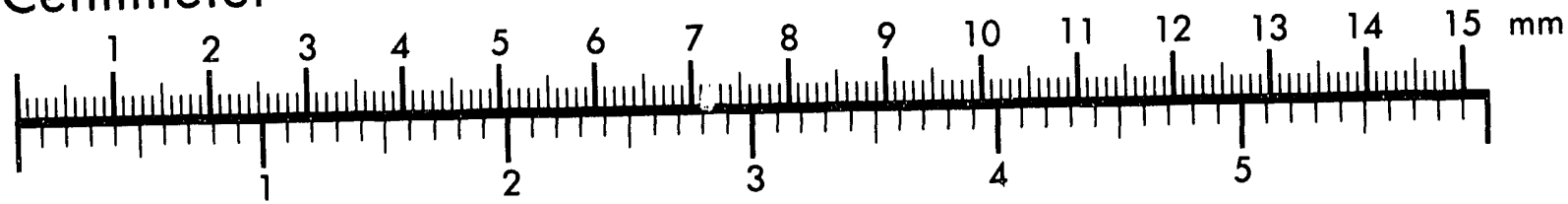
Inches
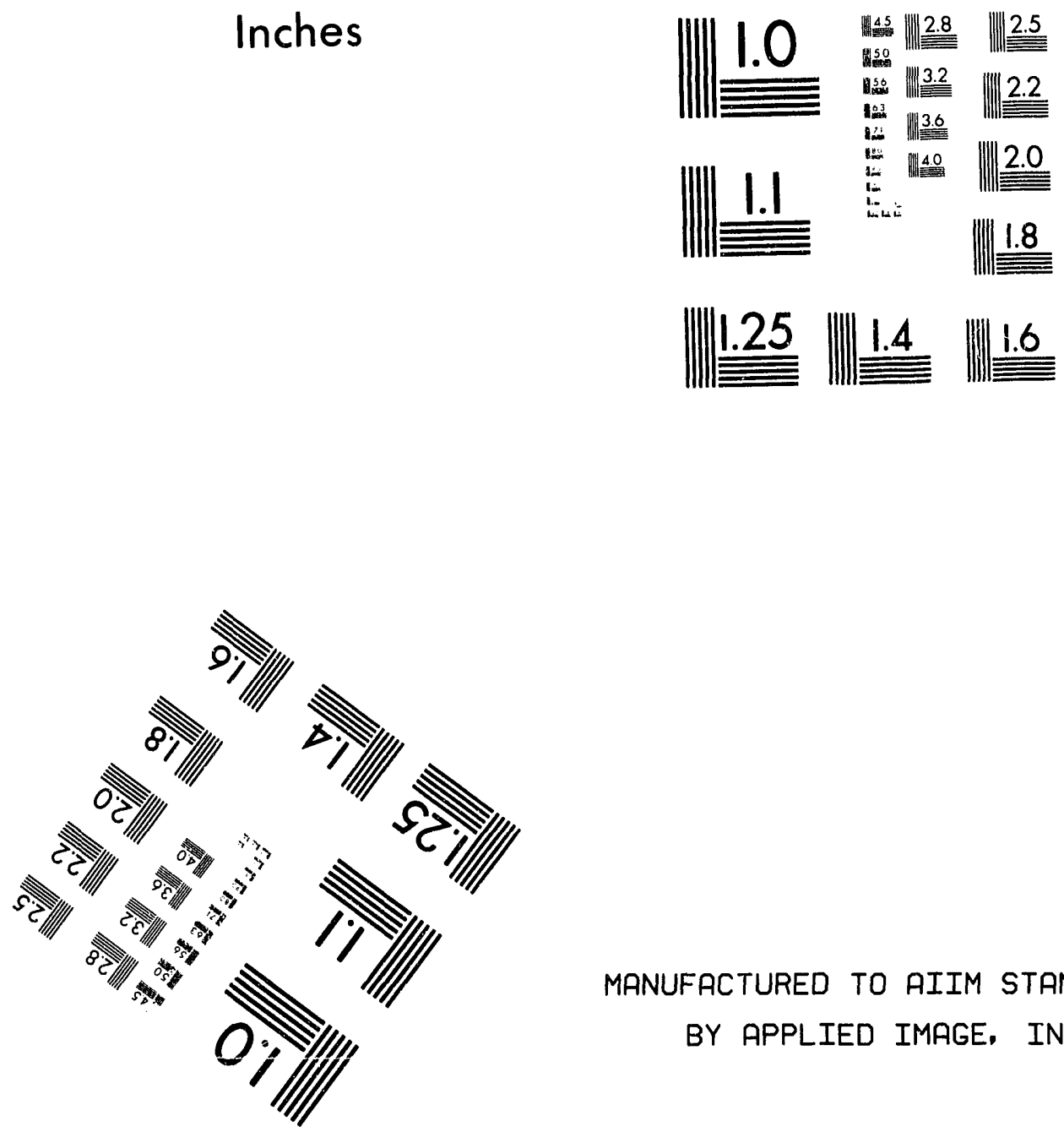

MANUFACTURED TO AIIM STANDARDS

BY APPLIED IMAGE, INC.

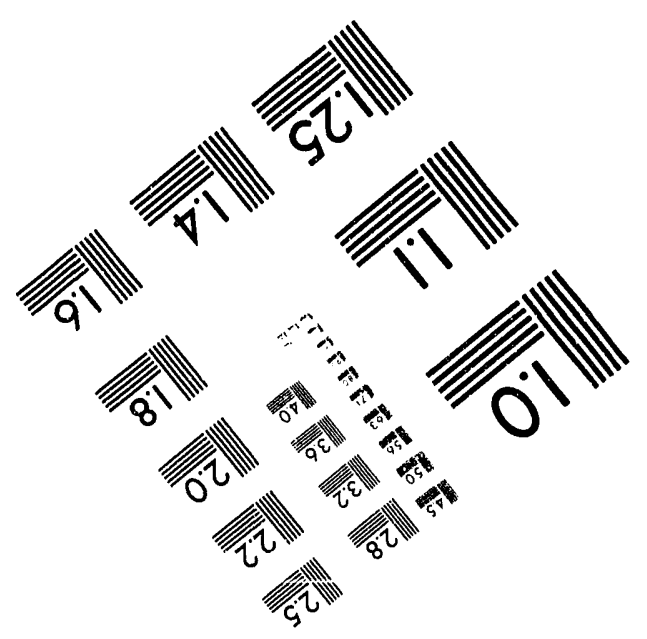



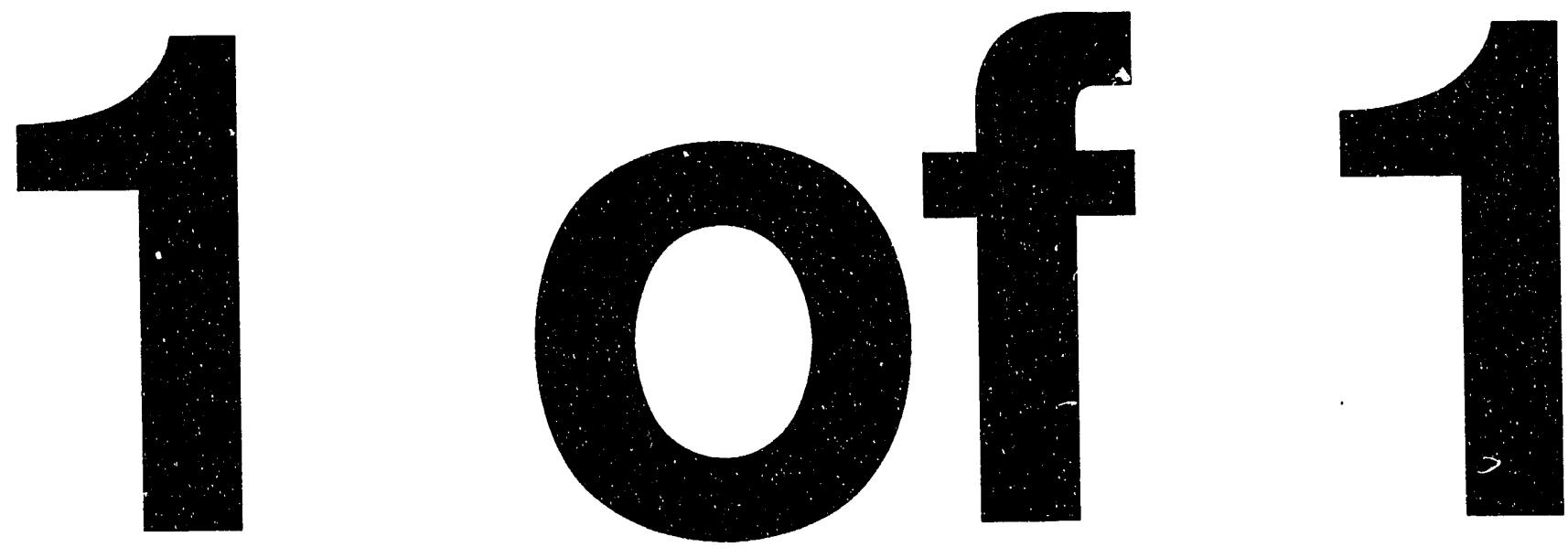
Office of Radiation Protection

\section{ANALYSIS OF ANOMALOUS DATA PRODUCED BY HARSHAW MODEL 8801 THERMOLUMINESCENT DOSIMETER CARDS}

E. Sonder

A. B. Ahmed

Date Published-May 1993

Prepared by the

OAK RIDGE NATIONAL LABORATORY

Oak Ridge, Tennessee 37831-6285

managed by

MARTIN MARIETTA ENERGY SYSTEMS, INC.

for the

U.S. DEPARTMENT OF ENERGY

under Contract DE-AC05-84OR21400 


\section{CONTENTS}

Page

LIST OF FIGURES $\ldots \ldots \ldots \ldots \ldots \ldots \ldots \ldots \ldots \ldots \ldots$

LIST OF TABLES $\ldots \ldots \ldots \ldots \ldots \ldots \ldots \ldots \ldots \ldots \ldots \ldots \ldots \ldots \ldots \ldots$ vii

ABSTRACT $\ldots \ldots \ldots \ldots \ldots \ldots \ldots \ldots \ldots \ldots \ldots \ldots \ldots \ldots \ldots \ldots \ldots$

1. INTRODUCTION $\ldots \ldots \ldots \ldots \ldots \ldots \ldots \ldots \ldots \ldots \ldots \ldots$

2. DESCRIPTION OF THE TLD SYSTEM $\ldots \ldots \ldots \ldots \ldots \ldots .2$

3. ANOMALOUS GLOW CURVES $\ldots \ldots \ldots \ldots \ldots \ldots \ldots \ldots$

3.1 FREQUENCY OF OCCURRENCE AND

GLOW CURVE SHAPES $\ldots \ldots \ldots \ldots \ldots \ldots \ldots \ldots \ldots, 3$

3.2 REPRODUCIBILITY OF ANOMALOUS GLOW CURVES - 6

4. EXCESS LUMINESCENCE PRODUCED BY THIN CHIPS $\ldots \ldots 7$

4.1 DISTRIBUTION OF EXCESS $D_{\circ}$ OF SUSPECT CHIP $3 \ldots .8$

4.2 VARIATION OF $\triangle D$ UPON REPEATED IRRADIATION OF SUSPECT CHIPS $\ldots \ldots \ldots \ldots \ldots \ldots \ldots \ldots \ldots \ldots$

5. HISTORY OF SUSPECT DOS:METERS $\ldots \ldots \ldots \ldots \ldots \ldots \ldots$

6. COMPARISON OF SENSITIVITY OF SUSPECT AND NORMAL

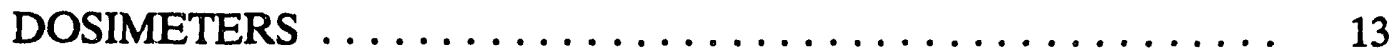

7. SUMMARY OF RESULTS $\ldots \ldots \ldots \ldots \ldots \ldots \ldots \ldots \ldots \ldots$

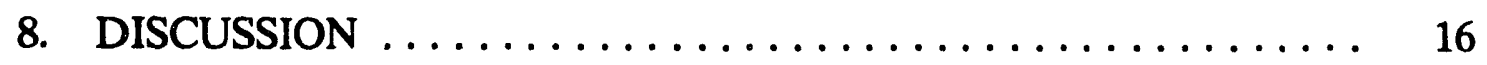

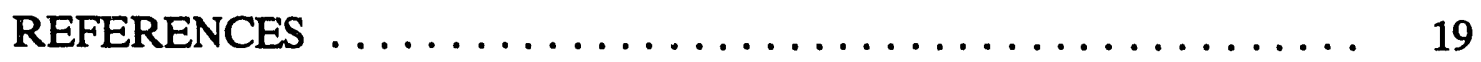




\section{LIST OF FIGURES}

\section{Figure}

1 Normal and anomalous glow curve shapes for $0.038-\mathrm{cm}$-thick LiF chips. Abscissa points 1-200 correspond to increasing temperatures between 50 and $300^{\circ} \mathrm{C}$

2 Normal and anomalous glow curve shapes for 0.0091-cm-thick LiF chips. The heavy dashed curve is a normally observed one. The numbered curves are unusual ones as discussed in the text. (a) Tests 1 and 2 . (b) Tests 3 and $4 \ldots \ldots$

3 Frequency distribution of difference between thin and thick chip response. (a) This distribution is for normal dosimeters. (b) This distribution is for dosimeters that have yielded

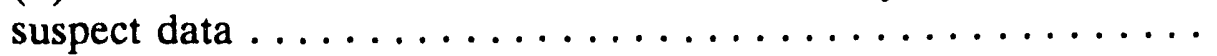

4 Frequency distribution of $\Delta \mathrm{D}$ of suspect dosimeters as a function

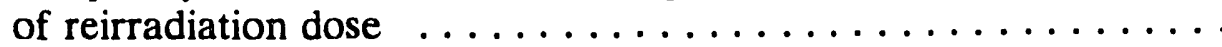

5 Response difference between thin and thick chips of two suspect dosimeters as a function of repeated gamma or background irradiations. Anneal number 4, marked with S, were the routine field dosimeter measurements on the basis of which the dosimeters were declared "suspect." Anneal numbers 1-3 were from earlier anneals or field assignments; anneal numbers 5-7 were obtained after background irradiation for various times ............

6 Response history of "suspect" and "normal" dosimeter cards. The data are from routine field use of the cards (circles) and anneals after short-term storage (squares) $\ldots \ldots \ldots \ldots \ldots$ 


\section{LIST OF TABLES}

Table

Page

1 Frequency of occurrence and recurrence of anomalous glow curves $\ldots \ldots \ldots \ldots \ldots \ldots \ldots \ldots \ldots \ldots \ldots \ldots \ldots \ldots \ldots \ldots$

2 Comparison of irradiated suspect and normal dosimeters ...... 15 


\title{
ANALYSIS OF ANOMALOUS DATA PRODUCED BY HARSHAW MODEL 8801 THERMOLUMINESCENT DOSIMETER CARDS
}

\author{
E. Sonder and A. B. Ahned
}

\begin{abstract}
A large number of dosimeters that have produced abnormal data during field assignment have been stored, reirradiated, and studied. Results are summarized and comparisons are made with normal dosimeters. Summarized here are anomalous glow curve shapes, distributions of anomalies in the residual luminescent responses, and historical and repeat-irradiation behavior of abnormal dosimeters. The results indicate that by far the most frequent abnormal data involve elevated readings from Chip 3, accompanied by excess luminescence at temperatures higher than that of the normal radiation produced band. There is no sharp division between normal and abnormal dosimeters (dosimeters yielding excess luminescence at high temperature). Rather, dosimeters exhibit a continuum of behavior from very good (little high temperature luminescence) to clearly abnormal behavior. The excess luminescence emitted at high temperature in abnormal dosimeters is not proportional to absorbed dose; it has a radiation-independent average value that depends on the dosimeter but varies erratically above and below that average for consecutive anneals. At relatively high radiation exposures ( $>100 \mathrm{mR}$ ), the amount of excess high temperature luminescence becomes unimportant and abnormal data are rare.
\end{abstract}

\section{INTRODUCTION}

The personnel external dosimetry system at Martin Marietta Energy Systems, Inc., facilities is based on thermoluminescent lithium fluoride (LiF) chips which, upon heating, emit light in proportion to previously absorbed radiation dose. ${ }^{1}$ This system produces a fraction of a percent false readings, most often at low doses; these false readings usually involve erroneous indications of low-energy X-ray or beta-ray exposure. It would be desirable to determine, in all cases, whether there is a true exposure or whether it is a false response of one of the dosimeter chips. At the present time such an attempt is made routinely ${ }^{2}$ by studying the glow curves (light emitted vs temperature during read out) of all chips of all returned dosimeters. However, such studies are tedious and not perfectly satisfactory. The work reported here was performed in order to discover whether any patterns exist in LiF dosimeter 
anomalous results, which might be useful in indicating whether particular positive readings are valid.

In the present study, we document the major anomalies observed in dose readings and curve shapes and estimate their frequency and repeat behavior upon reirradiation. The results will show that, by far, the predominant problem consists of false positive readings from the thin Chip 3; these false readings are usually accompanied by irregular glow curve shapes. Once a chip gives bad results, its probability of giving future excess readings is elevated. Moreover, the history of suspect dosimeters ${ }^{*}$ often indicates a previous tendency towards elevated readings for the same chip.

\section{DESCRIPTION OF THE TLD SYSTEM}

The Model 8801 dosimeters ${ }^{1}$ used for routine personnel dosimetry contain four $\mathrm{LiF}$ chips. For the present study we will ignore Chip 4 which is made from ${ }^{2} \mathrm{Li}$-enriched material in order to respond to neutrons. Chips 1 and 2 are identical 0.038-cm-thick $\mathrm{LiF}$ chips; they are normally shielded with plastic or copper in order to give an indication of the gamma energy range. Chip 3 is made of the same material but is much thinner $(0.0091 \mathrm{~cm})$. It is covered only by a thin Mylar ${ }^{\star}$ window in order to respond to low-energy X-rays and electrons. Under normal circumstances the ratios of responses of the different chips of a given dosimeter give an indication of the type of exposure, while the intensity of the luminescence emitted during processing is used to calculate dose received. The readout of exposed dosimeters consists of heating the $\mathrm{LiF}$ chips from 50 to $300^{\circ} \mathrm{C}$ over a 10-s interval, and then holding the cards at $300^{\circ} \mathrm{C}$ for $3.3 \mathrm{~s}$. At such rapid heating rates, the chips are significantly stressed. During the heating cycle, the emitted light of each chip is measured 200 times at equal time intervals; that data is used to plot glow curves and to calculate radiation dose equivalents.

As part of the normal personnel dosimetry procedures, ${ }^{2}$ glow curves of all returned field dosimeters are checked for anomalies. Dosimeters that exhibit unusual glow curves are inspected and sometimes removed from the reusable dosimetry inventory. More important, if an unusual glow curve is accompanied by a dose readout greater than the detection limit $\left(\mathrm{L}_{\mathrm{D}}\right){ }^{3}$, that datum is labeled "suspect" and procedures for handling suspect dosimeters are initiated. These include storage and reread of the dosimeter, investigation of the dosimeter's dose history, and professional (but largely subjective) judgement of whether the suspected dose is valid. The procedures also require extensive paperwork and interviews with the employees

\footnotetext{
- Suspect dosimeters: those that yield questionable positive readings and anomalous glow curves.
} 
who wore the suspect dosimeters. Techniques for discovering and removing, prior to assignment, dosimeters that have a higher probability than normal of yielding anonalivus . . sults could decrease the numbei of suspect data.

\section{ANOMALOUS GLOW CURVES}

\subsection{FREQUENCY OF OCCURRENCE AND GLOW CURVE SHAPES}

For routine personnel monitoring, dosimeters are kept in the field for 3 months; approximately 5 months elapse between "anneal for assignment" and "readout." Thus, most dosimeters will have an accumulated gamma dose due to 5-months' background radiation of approximately $16 \mathrm{mR}$ plus any added dose due to occupational exposure. For a typical quarterly exchange, which for ORNL and K-25 involves approximately 12,000 dosimeters, approximately 300 indicate positive exposures (i.e., readings of at least $10 \mathrm{mrem}$ above expected background of deep dose or $30 \mathrm{mrem}$ above background of shallow dose). On the other hand, study of the doses and glow curves obtained during readout indicates that an additional 100-200 dosimeters (out of the 12,000 ) are yielding suspect data from at least one of the chips. A fraction of these suspect results will, upon further investigation, be judged to be indicative of a positive but uncertain exposure. Almost all of the suspect results are for low dose readings, within a factor of 3 of the detection limit, $L_{D}$. For higher exposures, the TLD dosimeters are much more reliable.

In Figs. 1 and 2, glow curve shapes observed in dosimeters returned after assignment are reproduced. All of these dosimeters were subjected to $\sim 21$ weeks of gamma-ray background radiation; they received no known additional dose. The curves labelled "NORMAL" exhibit light emission with a maximum near Channel 150 for the 0.038-cm-thick Chip 1 or 2 (Fig. 1) and near Channel 125 for the 0.0091 -cm-thick Chip 3 (Fig. 2). This emission is due to the so-called \#4 and \#5 emission bands 4 that have maxima near $200^{\circ} \mathrm{C}$. The reason the emission appears at a lower channel for the thinner chip is that the heating rate in this lower mass chip is faster than it is in the thick'r and heavier chips.

An example of an abnormality occasionally observed in Chips 1 or 2 (the thick chips) is also shown in Fig. 1. It consists of emission at low temperatures, the band usually being much broader than the normal $200^{\circ} \mathrm{C}$ peak. A different anomaly, which occurs less frequently, consists of broad emission occurring at higher temperatures, so that it only gives rise to an extended tail at the high- and possibly low-temperature sides of the normal emission peak. 


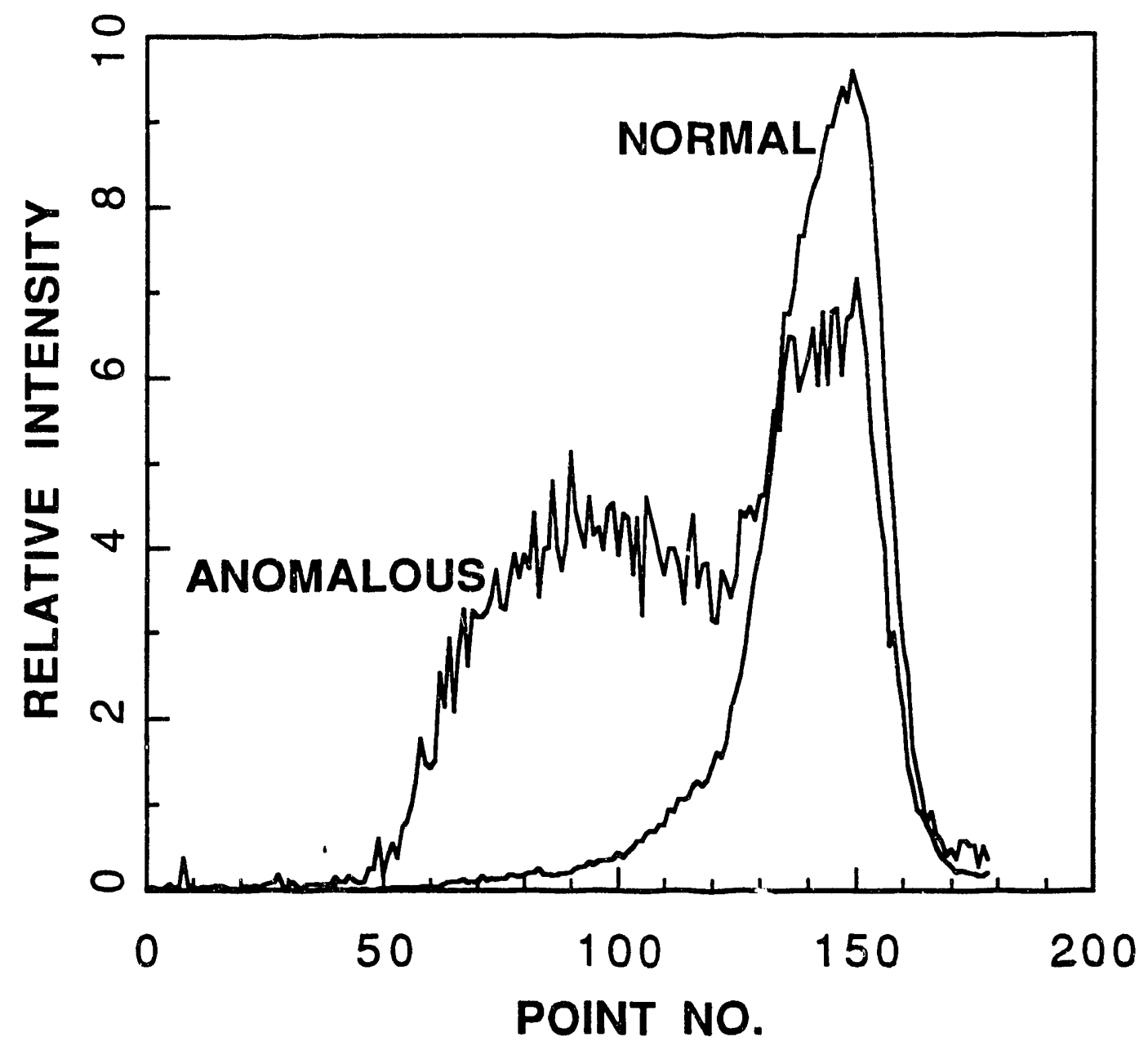

Fig. 1. Normal and anomalous glow curve shapes for 0.038-cm-thick LiF chips. Abscissa points $1-200$ correspond to increasing temperatures between 50 and $300^{\circ} \mathrm{C}$. 

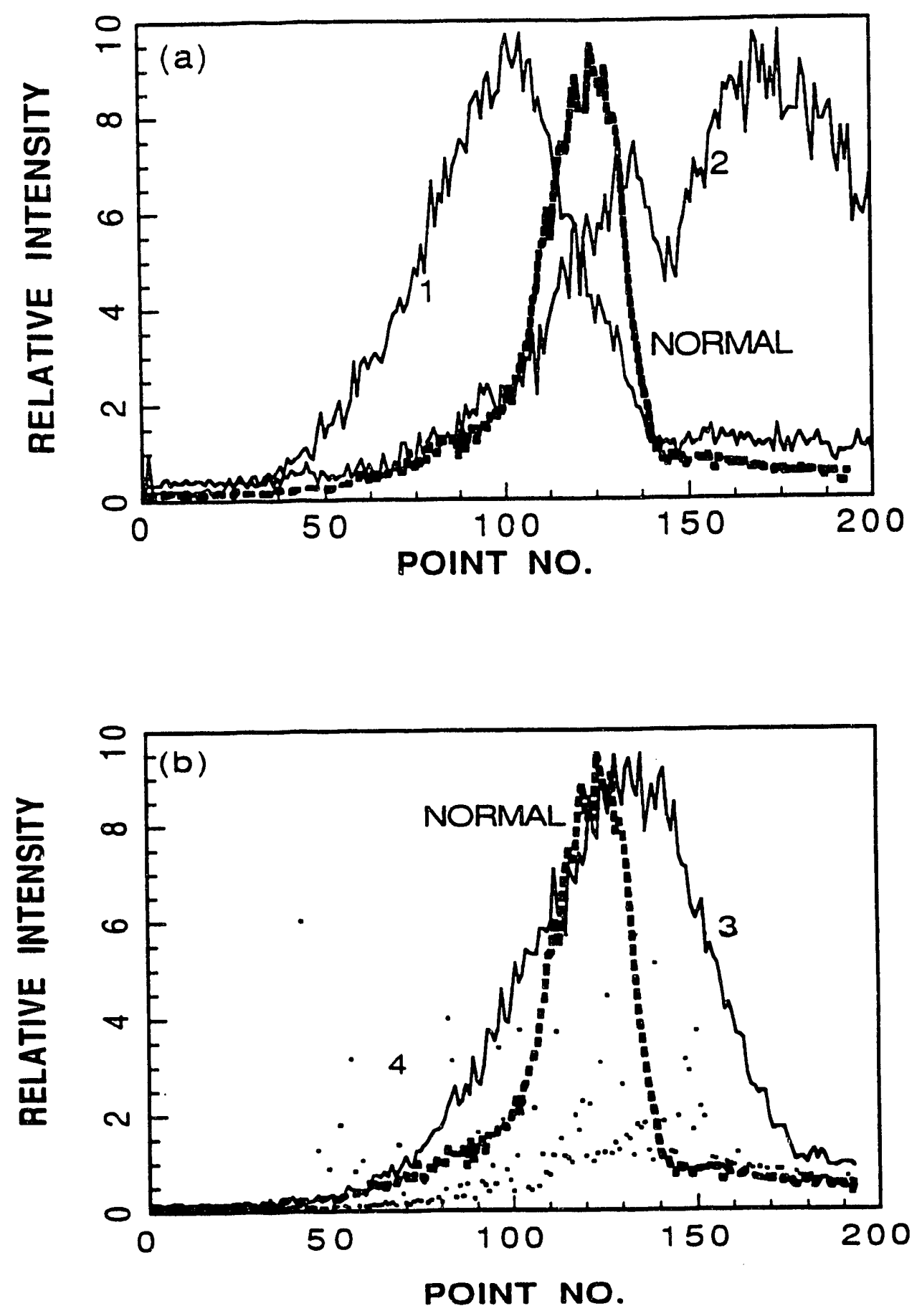

Fig. 2. Normal and anomalous glow curve shapes for $0.0091-\mathrm{cm}$-thick $\mathrm{LiF}$ chips. The heavy dashed curve is a normally observed one. The numbered curves are unusual ones as discussed in the text. (a) Tests 1 and 2. (b) Tests 3 and 4. 
Abnormalities in Chip 3 (the thin chip) are much more frequent. They can be divided into four classes, examples of which are shown in Fig. 2(a) and (b). Curve 1 depicts a curve with a broad emission at low temperature, analogous to the anomialous emission shown in Fig. 1 for thick chips. In Curve 1, the abnormal emission is large enough so that no evidence of the normal emission is evident. A variation of this behavior produces a curve similar to the anomalous curve of Fig. 1, in which both low-temperature emission and the normal luminescence is observed.

In Curve 2, a broad, intense emission appears at high temperatures. This emission can be intense enough to completely swamp the normal emission band, or it can be so small as to appear only as a tail on the high-temperature side of the normal emission. Most commonly, two clearly defined peaks can be observed. This type of anomaly is by far the most frequently observed one.

In a few cases, emission at both lower and higher temperatures than that for the normal emission band occurs. This behavior produces glow curves with a maximum near the normal temperature, but with excessive band widths and/or large tails at both high and low temperatures. Such an example is reproduced as Curve 3 in Fig. 2(b). The fourth class of anomaly, occasionally observed in Chip 3, is also depicted in Fig. 2(b) as Curve 4. It consists of extremely noisy data.

An estimate of the frequency of occurrence for the anomalies described above is presented in Table 1 . Column 2 gives the number of anomalous cards observed in approximately 10,000 dosimeters returned from the field after 21 weeks.

\subsection{REPRODUCIBILITY OF ANOMALOUS GLOW CURVES}

It would be useful to know the probability of recurrence of anomalous behavior of a dosimeter chip that has once exhibited such behavior. In order to gain some information on such recurrence, a large number of rerun data of anomalous dosimeters were examined. During routine personnel dosimetry operations, ${ }^{2}$ dosimeters yielding anomalous glow curves are removed from the reusable inventory and are put aside. They can then be reread 1 to 3 months later after having absorbed 4-12 $\mathrm{mR}$ of background gamma radiation. The last two columns of Table 1 indicate the recurrence rate for the different classes of curve anomalies. For the thick chips, of which only three exhibited anomalous behavior, all three reproduced a low-temperature band or tail when rerun after 2 months. For one of the three dosimeters, the tail, although quite observable, was low enough that under normal circumstances the dosimeter would have passed as "normal." Therefore, only two-thirds are indicated as reproducing the anomalous behavior. For thin chips, the probability of reproducing anomalies is also very high. For the most often observed anomalous curve shape (high-temperature peak or tail), once a chip exhibits this behavior, the probability is close to $100 \%$ that the behavior recurs. 
For the next most often observed anomaly, the broad band, only a quarter of reexamined dosimeters reproduce the identical behavior; however, another $50 \%$ exhibit other anomalous behavior, most often a high-temperature peak. Only dosimeters exhibiting low-temperature bands or high-noise behavior gave a probability of less than $50 \%$ for reproducing suspect behavior.

Table 1. Frequency of occurrence and recurrence of anomalous glow curves

\begin{tabular}{|c|c|c|c|}
\hline \multirow{2}{*}{$\begin{array}{l}\text { Chip/ } \\
\text { anomaly }\end{array}$} & \multirow{2}{*}{$\begin{array}{c}\text { Number of } \\
\text { anomalies in } \\
10,000 \text { field cards }\end{array}$} & \multicolumn{2}{|c|}{$\begin{array}{l}\text { Recurrence yielding } \\
\text { similar shape on rerun }\end{array}$} \\
\hline & & Number & Percent \\
\hline $\begin{array}{l}\text { Thick/ } \\
\text { Low T band } \\
\text { (Fig. 1) }\end{array}$ & 3 & 2 & 66 \\
\hline $\begin{array}{c}\text { Thin/ } \\
\text { Low T band } \\
\text { [Curve 1, Fig. 2(a)] }\end{array}$ & 10 & 3 & 30 \\
\hline $\begin{array}{c}\text { Thin/ } \\
\text { High T tand } \\
\text { [Curve 2, Fig. 2(a)] }\end{array}$ & 164 & $30^{\circ}$ & $\sim 100$ \\
\hline $\begin{array}{c}\text { Thin/ } \\
\text { Broad band } \\
\text { [Curve 3, Fig. 2(b)] }\end{array}$ & 31 & $8^{b}$ & 26 \\
\hline $\begin{array}{l}\text { Thin/ } \\
\text { Noisy signal } \\
\text { [Fig. 2(b)] }\end{array}$ & 13 & 3 & 23 \\
\hline
\end{tabular}

"From sample of 30.

${ }^{b}$ Plus $50 \%$ other anomalies.

\section{EXCESS LUMINESCENCE PRODUCED BY THIN CHIP}

The glow curve shape anomalies discussed in Sect. 3 appear to be related to incorrect dose readings; however, there is not a total correspondence. Unusual glow curves are occasionally associated with normal background readings, and some dosimeters that have been stored so that they are irradiated only with normal 
background read high and exhibit nearly normal glow curves. Moreover, it is not possible to devise a fixed criterion for deciding whether a particular glow curve is "normal" or "suspect." There is a gradation of glow curve shapes from clearly suspect to perfestly normal, and the decision for borderline cases is subjective. The relation between curve shape and excess dose response is statistical (i.e., for a population of cards there is a correlation between false elevated doses and abnormal curve shapes; but for any single card, an unusual curve shape does not predict excess dose readout nor is excess dose necessarily accompanied by an unusual curve shape).

In this section we considei more closely the quantity of luminescence emitted from the most often suspect Chip 3. As stated in Sect. 3.1, by far the largest fraction $(\sim 97 \%)$ of the dosimeters returned every quarter have absorbed only background gamma radiation of approximately $16 \mathrm{mrad}$. Of the dosimeters that have been exposed to significant occupational radiation (deep or shallow dose equivalent greater than $-2 * L_{\mathrm{D}}$ ), at least three-fourths of them exhibit high values for more than one chip. In contrast, most false positive readings involve high readings only for Chip 3 . In order to obtain a more quantitative assessment of the dose response of normal vs suspect Chip 3, we have gathered and compared dose information for a large number of dosimeter cards. The difference in luminescence yield of Chip 3 vs Chip 1 (or 2) is a convenient parameter to study the distribution and reproducibility of Chip 3 response in a somewhat quantitative manner; subtraction of the Chip 1 (or 2) response from that of Chip 3 normalizes for differences in background radiation received.

\subsection{DISTRIBUTION OF EXCESS $D_{0}$ OF SUSPECT CHIP 3}

We have studied this difference in element readings, $\Delta D=D_{3}-\left(D_{1}+D_{2}\right) / 2$, (where the subscripts refer to the chip number) for groups of dosimeters after three types of treatment: 1) normally returned field dosimeters (i.e., dosimeters assigned and worn in the field for 3-5 months), 2) dosimeters that remained in homes and therefore received only background gamma irradiation, ${ }^{5}$ and 3 ) dosimeters that had been removed from the pool because of previous suspect behavior. Many of these suspect dosimeters were examined repeatedly after a number of subsequent gamma irradiations, either from background or from a ${ }^{137} \mathrm{Cs}$ source.

Figure 3 shows how $\Delta \mathrm{D}$ is distributed for two groups of dosimeters. Distribution (a) is for approximately 200 "normal" dosimeters, exposed only to background gamuna radiation (type 2 of previous paragraph); distribution (b) is for a sinilar group of suspect dosimeters (type 3 of previous paragraph) that had been stored approximately 1 year and had therefo e received $\sim 40 \mathrm{mrad}$ of gamma radiation. It is clear that the distribution of $\Delta D$ for normal dosimeters has a maximum near $10 \mathrm{mR}$, whereas previously segregated suspect dosimeters yield, upon background reirradiation, a maximum near $=0 \mathrm{mR}$ and a much wider distribution. 

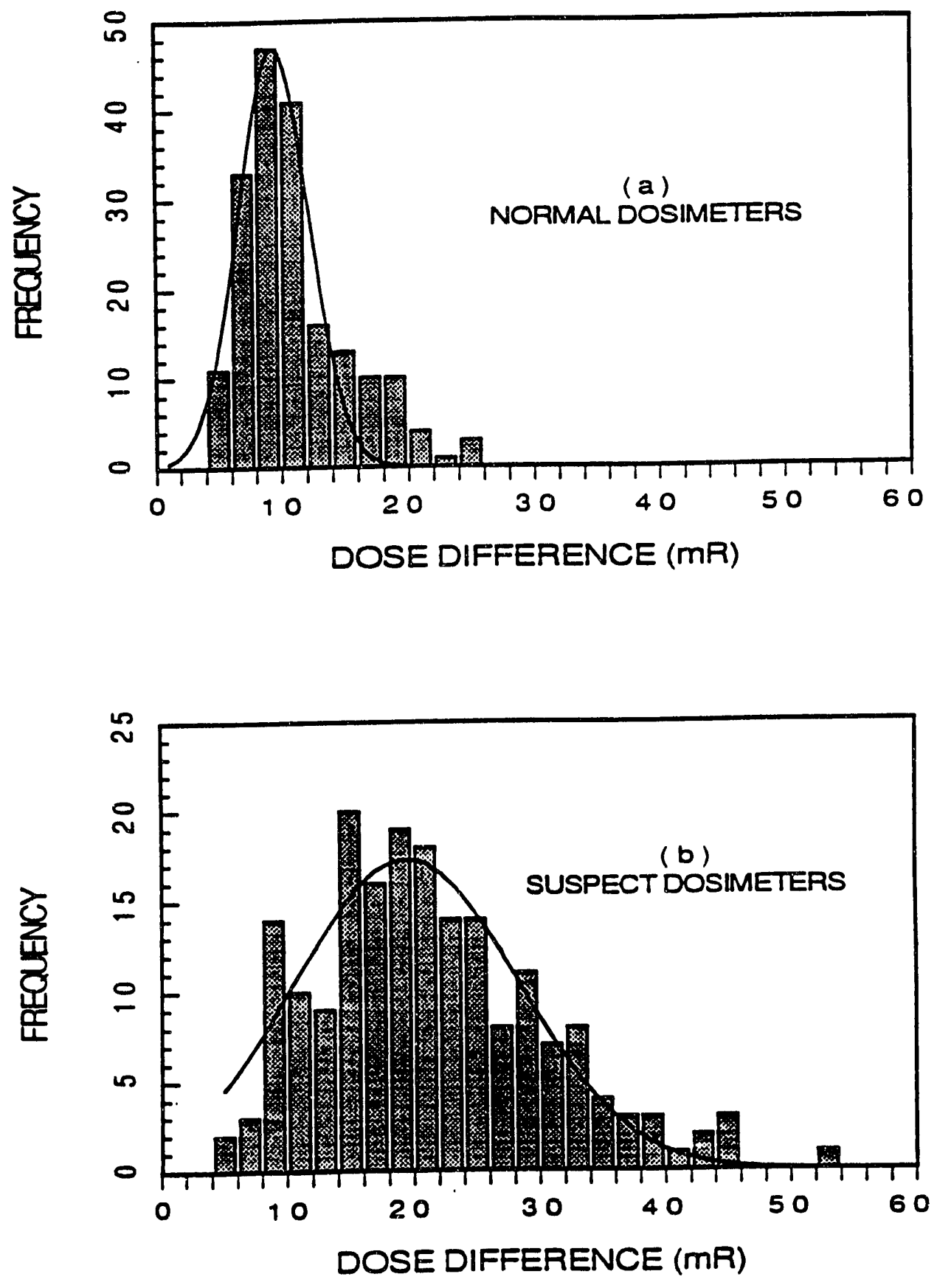

Fig. 3. Frequency distribution of difference between thin and thick chip response. (a) This distribution is for normal dosimeters. (b) This distribution is for dosimeters that have yielded suspect data. 
Distribution (a) of Fig. 3 indicates that, for most of the "normal" dosimeters, the difference between thin and thick chips is equal to the difference of the chips' residual responses, ${ }^{5} D_{0}(3)-D_{0}(1,2)=13-3$. However, the distribution exhibits a tail to $-25 \mathrm{mR}$. The excess high occurrences encompass about $15 \%$ of dosimeters. We interpret this tail as indicating that thin chips have a tendency to respond with small excess dose readings during routine dosimetry, and that such small excess readings occur more frequently than do actual "suspect" indications.

Distribution (b) of Fig. 3 indicates clearly that gamma reirradiation of previously declared suspect dosimeters produces a distribution of $\Delta D$ that is much broader than that of normal dosimeters and has a peak (most probable) value that is significantly larger than that for normal dosimeters. The difference between the distributions of Figs. 3(a) and (b) indicates that excess values of $\Delta D$ have a high probability of recurring after a year of storage. It should be reiterated (recall Sect. 3.2 and Table 1) that anomalous curve shapes similarly have a high probability of recurrence.

In order to determine whether the magnitude of absorbed dose affects the excess response of Chip 3, we separated from our supply of suspect dosimeters (group 3 as described in the first parageraph of this section) three sets of dosimeter. Each set was then reexposed to a different dose of background gamma radiation. The three distributions of the parameter, $\Delta \mathrm{D}$, are reproduced in Fig. 4. These distributions are similar and show no significant trend with irradiation dose. This result indicates that the excess values of $\Delta D$ stem largely from the residual response, $D_{o}$. If it were predominantly due to excess sensitivity of Chip 3, then the values of $\Delta D$ for these distributions would tend to move to higher values for the more heavily reirradiated sets.

\subsection{VARIATION OF $\triangle D$ UPON REPEATED IRRADIATION OF SUSPECT CHIPS}

We have taken a number of suspect cards and performed a series of repeat irradiations, both with normal background for times varying between 1 month and 1 year and with ${ }^{137} \mathrm{Cs}$ gamma rays." For most of these cards the parameter $\Delta \mathrm{D}$ decreased upon reirradiations immediately after the suspect result but remained significantly above the value of approximately 10 , typical for normal cards. In Fig. 5, data for two such cards are shown. The points indicated with an "S" (readout 4) are those for which suspect behavior was declared. Readouts 5 and 6 were performed after 4 and 12 months of storage, respectively; readout 7 was performed after 1 month of storage; readout 8 was performed after a ${ }^{137} \mathrm{Cs}$ gamma irradiation and 4 days of storage.

\footnotetext{
- These cards were normally stored in total darkness.
} 

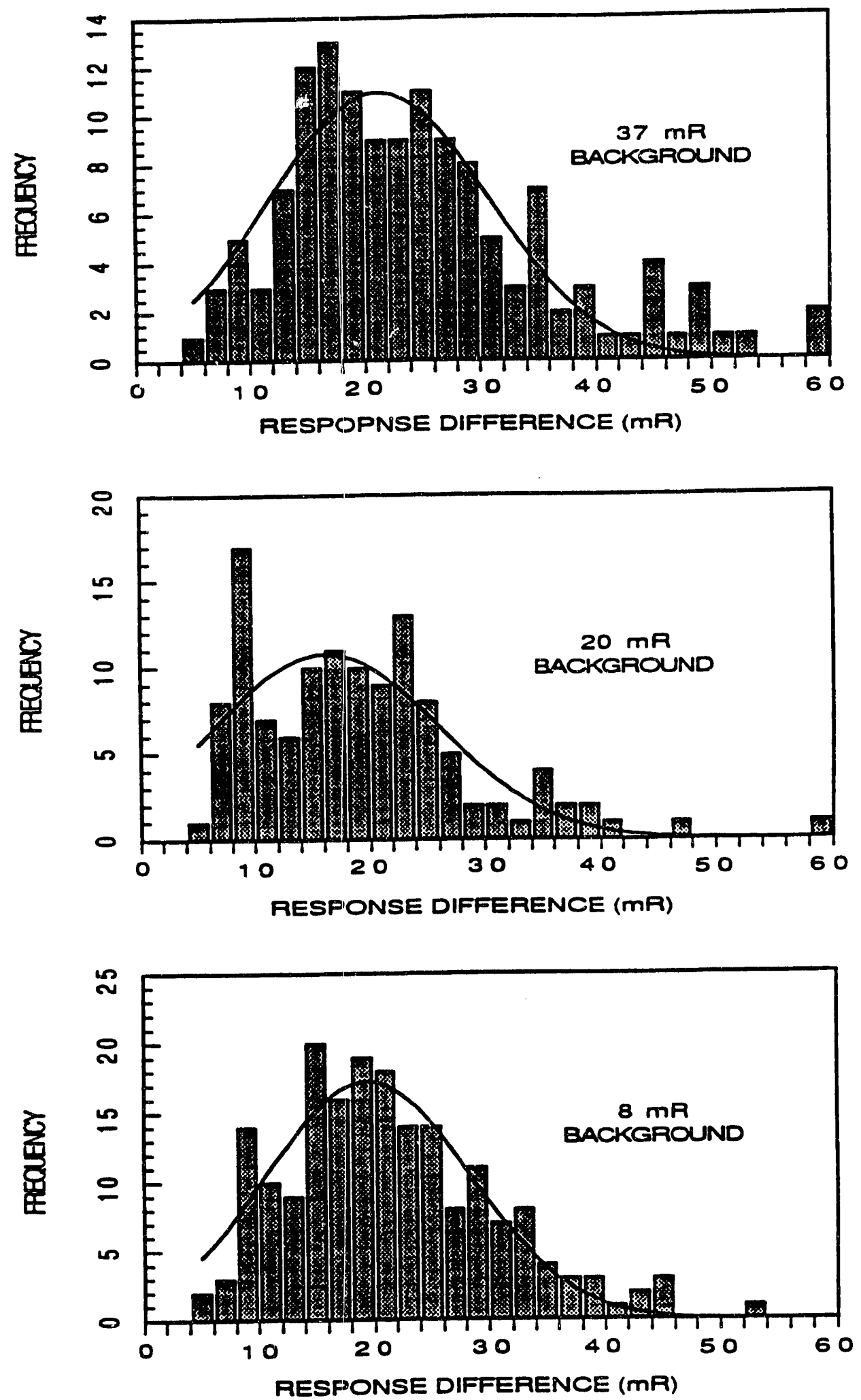

Fig. 4. Frequency distribution of $\Delta D$ of suspect dosimeter as a function of reirradiation dose. 


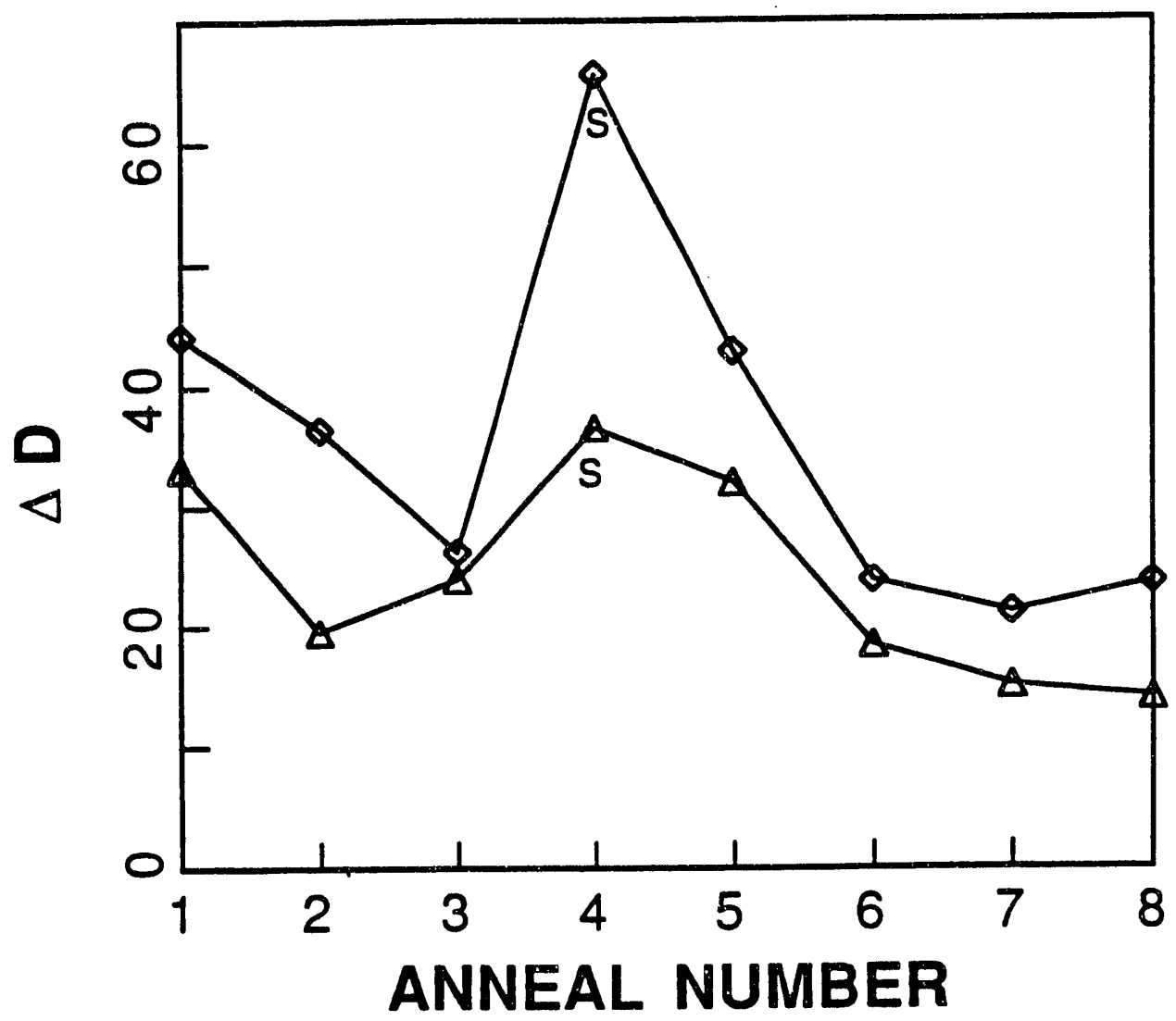

Fig. 5. Response difference between thin and thick chips of two suspect dosimeters as a function of repeated gamma or background irradiations. Anneal number 4, marked with S, were the routine field dosimeter measurements on the basis of which the dosimeters were declared "suspect." Anneal numbers 1-3 were from earlier anneals or field assignments; anneals numbers 5-7 were obtained after background irradiation for various times. 


\section{HISTORY OF SUSPECT DOSIMETERS}

In rinother attempt to find patterns in the repeat behavior of suspect dosimeters, we retrieved the radiation/readout history of dosimeters that had produced suspect data and compared the records with those of "normal" field dosimeters. For suspect dosimeters, values of $\Delta \mathrm{D}$ extracted from the historical record are often above $19 \mathrm{mR}$. For many of the suspect dosimeter chips, high values of $\Delta D$ appear early in their life; upon subsequent irradiations $\Delta D$ may be high or normal, but the probability of recurrent high values of $\Delta D$ is significantly elevated in this group. We were surprised to find that values of $\Delta D$ tended to be not as high for anneals performed within a few days of a previous anneal or readout and tended to be higher after a 21-week field assignment. In Fig. 6 we show two examples of how $\Delta D$ behaves during the life of a card, one for a typical "normal" card and another for a card that was eventually declared suspect. The points indicated by circles were obtained after field assignment of the dosimeters; for these, the dosimeter cards were encapsulated in holders and were exposed to background and possible occupational radiation (and some light) for approximately 21 weeks. Anneal points obtained after storage of less than -5 weeks (probably in the absence of light) are shown with square symbols. It should be pointed out that the history shown is for two specific dosimeter cards; there was great variation both in the magnitude of $\Delta \mathrm{D}$ and in the variation with repeat readout/anneals; data for most cards fell between the two data sets shown in Fig. 4. Moreover, some dosimeters that exhibited low values of $\Delta D$ for a number of cycles suddenly yielded high $\Delta D$ and anomalous glow curves, and others exhibited high values of $\Delta \mathrm{D}$ early in their life and lower ones later.

\section{COMPARISON OF SENSITIVITY OF SUPECT AIND NORMAL DOSIMETERS}

As an additional check to determine whether suspect dosimeters are influenced by excess sensitivity (rather than large $\Delta D$ ), we compared the sensitivity of two groups of dosimeters: one consisting of 65 dosimeters having previously been declared suspect, and the other consisting of an equal number of normal dosimeters. Both groups were irradiated identically with $100 \mathrm{mR}$ of ${ }^{137} \mathrm{Cs}$ gamma rays. As Table 2 indicates, the average of neither the deep nor shallow dose equivalent of the suspect dosimeters was larger than that of the normal ones. If the sensitivity of Chip 3 of the suspect dosimeters was elevated, its shallow dose average would be higher than that for normal dosimeters. Clearly this is not so. We did notice, however, that a significantly larger percentage of the suspect dosimeters caused the algorithm to calculate the dose equivalents via an inappropriate branch. A close look at the algorithm will show that calculation via the correct branch for ${ }^{137} \mathrm{Cs}$ requires that

- Sensitivity here refers to the proportionality constant relating actual dose with the measured luminescence. This constant is determined for each new dosimeter chip. (see ref. 8) 


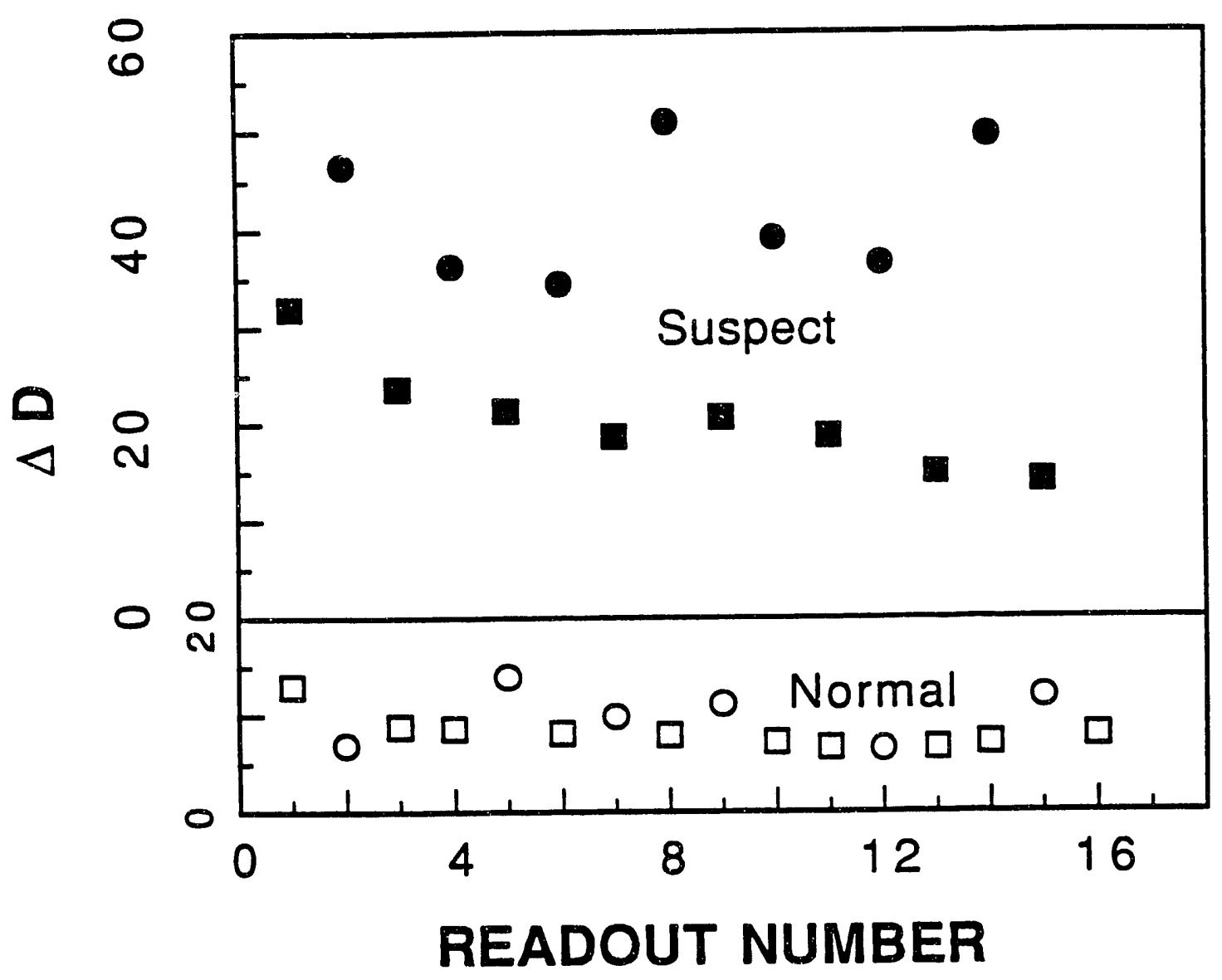

Fig. 6. Response history of "suspect" and "normal" dosimeter cards. The data are from routine field use of the cards (circles) and anneals after short-term storage (squares). 
Table 2. Comparison of irradiated suspect and normal dosimeters

\begin{tabular}{ccccc}
\hline \multirow{2}{*}{ Dosimeter } & \multicolumn{2}{c}{$\begin{array}{c}\text { Average dose } \\
\text { equivilent }(\mathrm{mrem})\end{array}$} & \multicolumn{2}{c}{$\begin{array}{c}\text { Going to } \\
\text { wrong branch }\end{array}$} \\
\cline { 2 - 5 } & Deep & Shallow & Number & Percent \\
\hline Normal & 99.4 & 99.4 & 1 & 0.15 \\
Suspect & 96.6 & 99.2 & 17 & 26.5 \\
\hline
\end{tabular}

$D_{3}<1.1 D_{1}$. At a dose of $100 \mathrm{mR}$, an excess of $10 \mathrm{mR}$ in $\Delta \mathrm{D}$ will be enough to produce the incorrect branching. Such a magnitude is consistent with the elevation of $\Delta \mathrm{D}$ of suspect dosimeters as discussed earlier (Sect. 4). Thus the results summarized in Table 2 support the proposition that most of the suspect behavior stems from an excess in $D_{o}$ rather than the sensitivity of Chip 3. They also show that the the type of dose errors we are disc'ssing here are limited to the dose range near the detection limit. For gamma ray doses greater than or equal to $100 \mathrm{mR}$, "suspect" dosimeters yield values not much different from "normal" ones, although the algorithm branches incorrectly more frequently.

\section{SUMMARY OF RESULTS}

In summary, after study of the history and repeat behavior of suspect and "normal" cards, we believe the anomalous high doses occasionally observed in Chip 3 tend to correlate with anomalous glow curves. Cards for which Chip 3 has once yielded suspect responses have a higher probability than do normal cards of exhibiting recurrent excess values of $\Delta D$ and excess luminescence at high temperature. Conversely, cards that frequently exhibit elevated values of $\Delta D$ have a higher probability than normal of eventually yielding suspect data. The excess luminescence of Chip 3, which is the usual cause of supect data designations, appears to be limited in magnitude. It is an important contribution for doses near the detection limit. However, for significant exposures (greater than $100 \mathrm{mR}$ ), this excess luminescence does not produce large errors. Thus the main problem connected with the "suspect" behavior discussed here occurs only in operations (like these at the Martin Marietta Energy Systems installations) where most of the workers are NOT exposed and where most dosimeters are returned with zero occupational dose. Among these (low-dose) dosimeters, a small but significant number can appear with suspect indications. 


\section{DISCUSSION}

Suspect behavior occurs rarely in thick chips; only three anomalous curves yielding high doses were observed in this study in approximately 10,000 cards. However, suspect behavior of the thin Chip 3 was much more frequent as indicated in Table 1. In view of the fact that considerable time and effort is expended for every suspect datum, two procedures would be desirable. One would consist of removing from the pool of cards dosimeters that have a high probability of yielding future suspect data; the other would involve the determination of a criterion for deciding when a suspect datum includes a real exposure and when it is clearly due only to dosimeter error. Since the effects described here are statistical, it is difficult to devise clear and simple rules either for setting suspect data to zero or for removing from the card inventory cards that would yield suspect data in the future.

However, there is a degree of repeatability in the behavior of dosimeter cards. Moreover, at least on a statistical basis, cards that have a relatively high probability of yielding suspect results for Chip 3 tend to show elevated values of $\Delta D$ and/or glow curve shapes with high temperature luminescence [Curve 2 of Fig. 2(a)] or a broad peak [Curve 3 of Fig. 2(b)]. Either or both of these characteristics can be used to remove from the card inventory cards that have a higher-than-normal probability of producing suspect data. Elevated values of $\Delta D$ could also be used to justify setting small suspect shallow dose readings to zero.

In order to decrease the number of suspect cards, the acceptance procedures could be modified to include an additional test-one that would identify some of the cards that have a higher-than-normal probability of producing future suspect data. The test would be performed in addition to initial ECC determination ${ }^{6}$ and neutron sensitivity testing; ${ }^{7}$ a third test, 10- to 20-mR gamma irradiation (or a 2- to 3-month storage to build up comparable background dose) would be performed, after which $\Delta \mathrm{D}$ would be calculated. Cards yielding glow curve shapes with peaks at high temperature and $\Delta D>\sim 20$ would be rejected.

Another possible method of identifying cards that have a higher-than-normal probability of producing suspect data would involve tracking values of $\Delta D$, obtained after anneals for cards in the regular inventory. Cards with frequently higher-thannormal values of $\Delta D$ would be removed.

Since the excess luminescence observed in suspect dosimeters appears to be relatively independent of the total dose, anneals before and after the assignment yielding the suspected reading can be used to estimate an "excess" value of $D_{o}$ to be applied to the suspect reading. This excess in $D_{o}$ 's would, for a significant fraction of suspect results, lower the calculated occupational dose below the lower reporting limit. Such a procedure would allow many suspect doses to be set to zero in a fairly objective and justifiable fashion. 
The rather frequent high-temperature luminescence accompanying suspect doses can also be used to estimate whether there has been a real radiation exposure. An assumption would be made that the luminescence in the normal band peaking at Channel 125 is due to radiation exposure while the luminescence in the high-temperature peak or tail is due to the chip. The relative areas would yield a correction factor for the suspected reading. Unfortunately, at the present time, the glow curve data cannot easily be extracted from the TLD REMS system supplied by the manufacturer. ${ }^{8}$ However, new programs to extract glow curve data and further testing may allow development of procedures for extracting more reliable information from suspect Chip 3 readings. 


\section{REFERENCES}

1. Harshaw Model 8800 Thermoluminescent Dosimetry System, using Type 8801, four-chip dosimeter cards. System is supplied by Solon Technology, Inc., Solon, $\mathrm{OH}$.

2. Procedure CEDS 2-1-80, "Results Validation," Rev. 2, Centralized External Dosimetry System Standard Operating Procedures and Quality Assurance Program Manual, Oak Ridge National Laboratory, Oak Ridge, TN.

3. U.S. Dept. of Energy Standard for Performance Testing of Personnel Dosimetry Systems, DOE-EH 0027, 1986.

4. R. G. Fairchild, G. Mattern, and K. Lengweiler, "Thermoluminescence of LiF (TLD 100): Glow Curve Kinetics," J. Appl. Phys., 49, 4523 (1978).

5. E. Sonder and A. B. Ahmed, Background Radiation Accumulation and Lower Limit of Detection in Thermoluminescent Beta-Gamma Dosimeters, ORNL/TM-11995, Oak Ridge National Laboratory, Oak Ridge, TN, 1991.

6. Procedure CEDS 2-1-95, "ECC Determination," Rev. 2, Centralized External Dosimetry System Standard Operating Procedures and Quality Assurance Program Manual, Oak Ridge National Laboratory, Oak Ridge, TN.

7. Procedure CEDS 2-1-20, "Quality Acceptance Testing of New TLD Cards," Rev. 3, Centralized External Dosimetry System Standard Operating Procedures and Quality Assurance Program Manual, Oak Ridge National Laboratory, Oak Ridge, TN.

8. "Harshaw/QS TLD Radiation Evaluation and Management System: User's Manual," distributed by Solon Technology, Inc., Solon, OH. 
ORNL/TM-12311

\section{INTERNAL DISTRIBUTION}

1-5. A. B. Ahmed

6. A. D. Arnwine

7. R. S. Bogard

8. D. S. Colwell

9. S. W. Croslin

10. E. Dixon

11. T. C. Dodd

12. R. W. Fields, Jr.

13. R. J. Gunter

14. J. B. Hunt

15. C. E. Maples

16. K. L. McMahan

17. G. T. Mei

18. K. L. Nugent

19. L. J. Schwanke
20. P. E. Shaver

21. K. R. Shaw

22. C. S. Sims

23. P. R. Smith

24. D. E. Somers

25-29. E. Sonder

30. M. L. Souleyrette

31. N. A. Teasley

32. M. Thein

33. Central Research Library

34-35. Laboratory Records

36. Laboratory Records-RC

37. ORNL Patent Section

38. ORNL Y-12 Technical Library

\section{EXTERNAL DISTRIBUTION}

39. Office of Assistant Manager for Energy Research and Development, U.S. Department of Energy, Oak Ridge Operations, P.O. Box 2001, Oak Ridge, TN 37831-8600.

40-41. Office of Scientific and Technical information, P.O. Box 62, Oak Ridge, TN 37831.

42. H. J. Monroe, U.S. Department of Energy, Oak Ridge Operations, P.O. Box 2001, Federal Building, MS-S334, Oak Ridge, TN 37831.

43. F. M. Cummings, U.S. Department of Energy, 785 DOE Place, Idaho Falls, ID 83402-4149.

44. J. J. Fix, Battelle-Pacific Northwest Laboratory, Battelle Boulevard, Richland, WA 99352.

45. R. A. Tawil, Harshaw/Bicron Radiation Measurement Products, 6801 Cochran Road, Solon, $\mathrm{OH} 44139$.

46. C. F. Wu, Waste Isolation Pilot Plant, P.O. Box 2078, Carlsbad, NM 88221. 

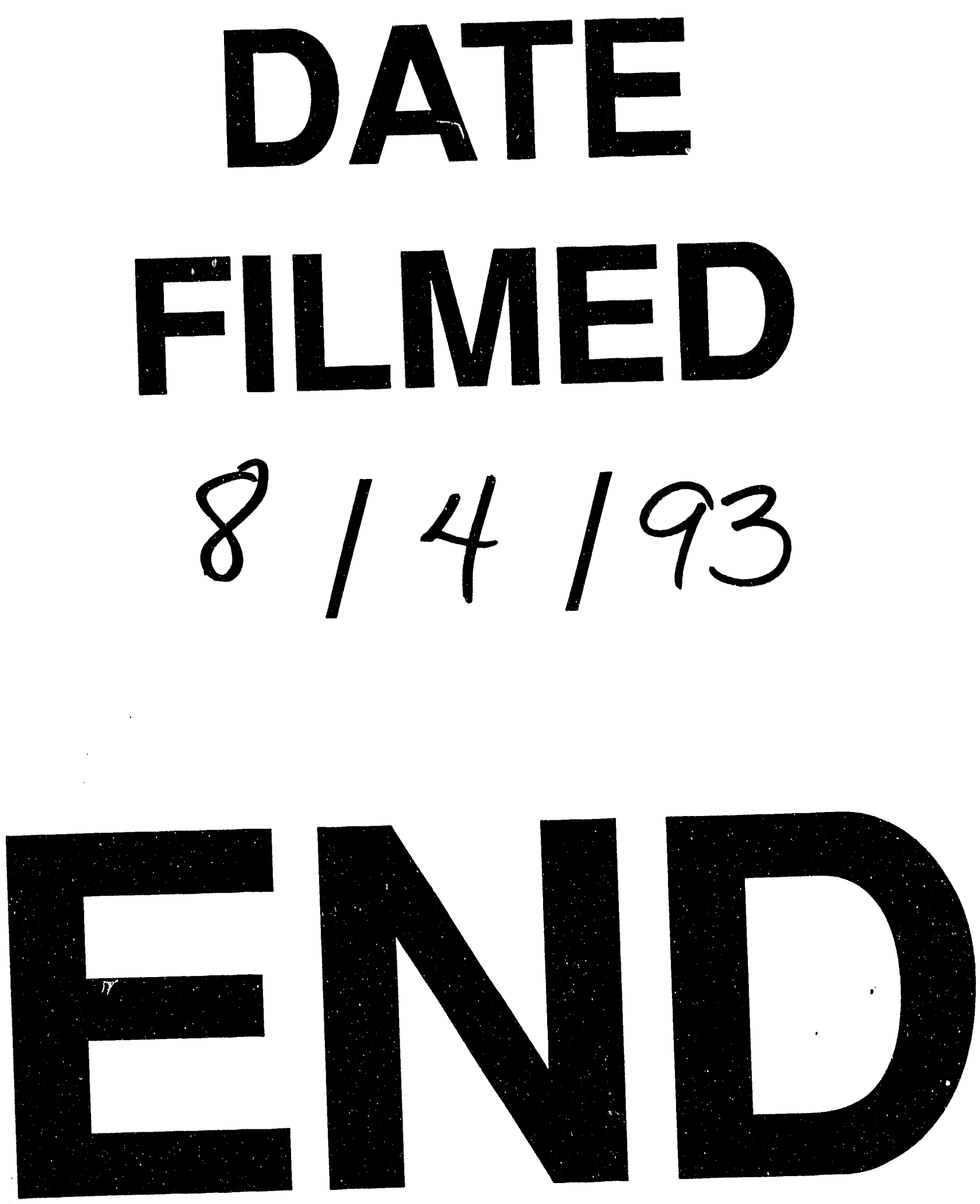
